\title{
New species of scuttle flies (Diptera: Phoridae) recorded from caves in Nevada, USA
}

\author{
R. Henry L. DISNEY ${ }^{(1, *)}$, Steven J. TAYLOR ${ }^{(2)}$, Michael E. SLAY ${ }^{(3)}$, Jean K. KREJCA ${ }^{(4)}$ \\ (1) Department of Zoology, University of Cambridge, Downing Street, Cambridge CB2 3EJ, UK; email: rhld2@hermes.cam.ac.uk \\ (2) Illinois Natural History Survey, Institute of Natural Resource Sustainability, University of Illinois1816 S. Oak Street (MC-652) \\ Champaign, Illinois 61820-6953, USA; email: sjtaylor@illinois.edu \\ (3) The Nature Conservancy, 601 North University Avenue, Little Rock, Arkansas 72205, USA; email: mslay@tnc.org \\ (4) Zara Environmental LLC, 1707 W FM 1626, Manchaca Texas 78652, USA; email: jean@zaraenvironmental.com \\ * corresponding author
}

\begin{abstract}
Five new species of scuttle fly are reported from caves in Nevada, USA, namely Aenigmatias bakerae Disney, Megaselia excuniculus Disney, M. krejcae Disney, M. folliculorum Disney, M. necpleuralis Disney and a female Megaselia that can not be named until linked to its male.
\end{abstract}

Key words: Diptera, Phoridae, new species, caves, USA

\section{INTRODUCTION}

Our knowledge of the scuttle flies (Diptera: Phoridae) reported from subterranean habitats in the USA has been recently expanded along with a revision of some of the identities and nomenclature for the records from the $19^{\text {th }}$ and $20^{\text {th }}$ centuries (Disney et al 2010). Subsequent records (Disney \& Campbell 2011) extended our knowledge of the most common of these species. It was therefore surprising when a biological survey of caves and a mine in White Pine County, Nevada produced an entirely new list of species, all but one of which proved to be undescribed. The new species are described below.

\section{METHODS}

The specimens were collected by hand and were preserved in alcohol (70-80\% ethanol) and were mounted on slides in Berlese Fluid (Disney 2001) and described by RHLD. The morphological terms employed in the descriptions are based on thos covered by Disney (1994), with some amendments (Disney et al 2010).

\section{RESULTS}

The depository for the specimens is the University of Cambridge Museum of Zooloogy (UCMZ).
Aenigmatias Meinert, 1890

A dozen species are known from the Nearctic and $\mathrm{Pa}-$ laearctic Regions. The males are keyed by Disney (2002) and some females are covered by Borgmeier (1963), Schmitz (1955) and Disney (1993).

\section{Aenigmatias bakerae Disney, sp. nov.}

\section{Description}

Male. A generally brown species. Frons with a pair of pre-ocellar bristles level with the anterior ocellus and in front of the posterior ocelli. Postpedicels brown and arista very short haired (appearing bare at low magnifications). Palps brown and each with 7 bristles at its tip. Thoracic scutellum with 7 bristles each side. Abdominal tergites with short hairs dorsally but longer ones at sides, the longest being on T6. Hypopygium as Fig. 1a. Venter grey. All legs brown. Front tibia and tarsus as Fig. 1b. Mid tibia with an anterior hair palisade in addition to the dorsal one; and likewise the hind tibia, but it has 2-3 gaps. Wings 1.9-2.0 mm long. Costal index 0.49. Costal ratios $6.5: 1.5: 1$. Costal cilia $0.03-0.04 \mathrm{~mm}$ long. 11 hairs on Rs, Vein Sc vestigial. 6 bristles on axillary ridge. All veins brown but 7 pale. Veins 4-7 do not reach wing margin, and in the case of 7 the outer third is missing. Membrane lightly tinged grey. Haltere brown.

\section{Material}

Holotype male, NEVADA: White Pine Co., Pine Cone Cave, 17 July 2007, J. K. Krejca, M. Horner, M. E. Slay, C. M. Slay and B. Roberts (470 NPS-GRBA, Project 411, Catalog 7157) (UCMZ, 31-131). 

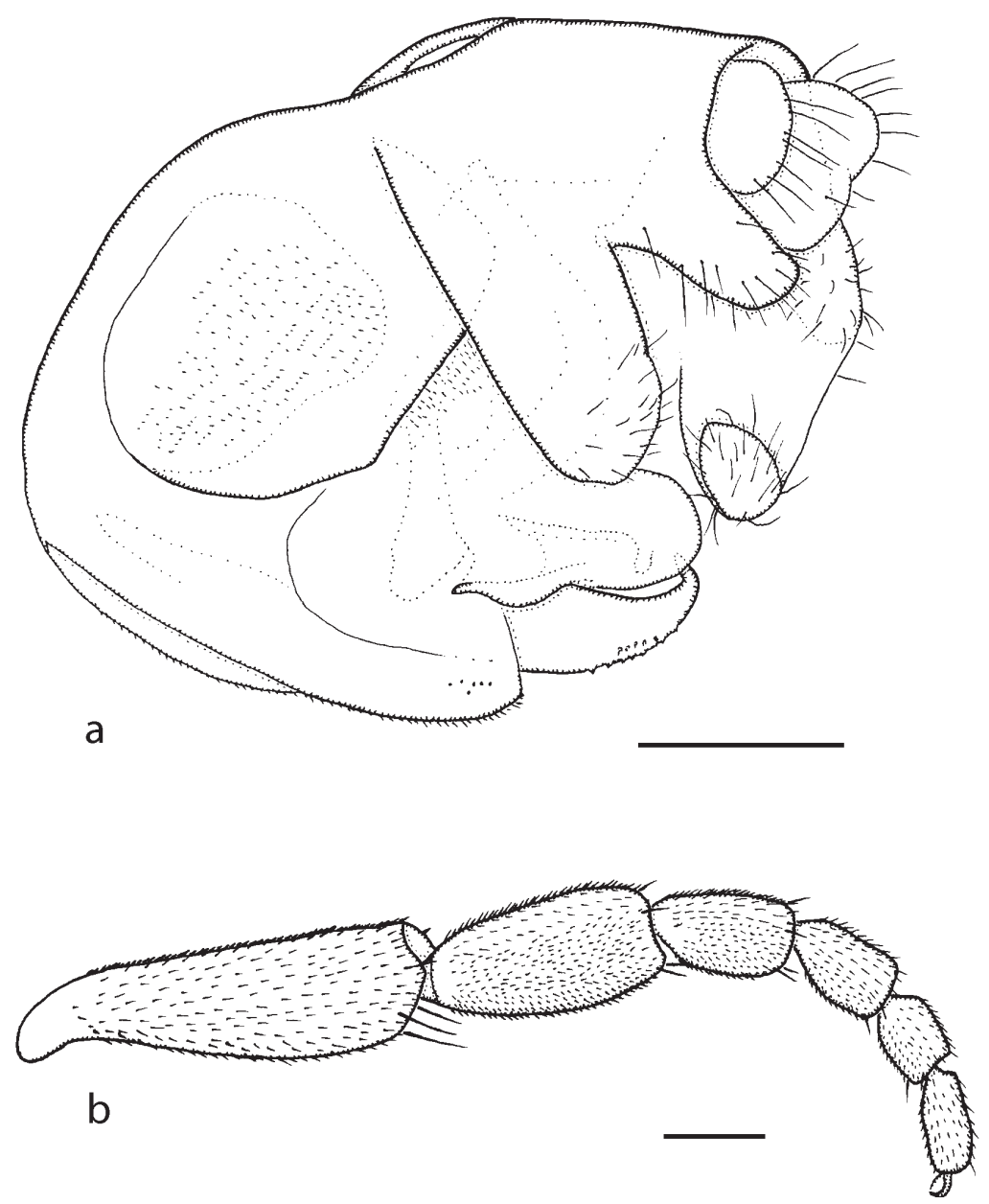

Fig. 1. Aenigmatias bakerae sp. nov. male. a, left face of hypopygium; b, front tarsus. Scale bars $=0.1 \mathrm{~mm}$.

\section{Habitat}

Pine Cone Cave is at an elevation of $3020 \mathrm{~m}$, and the specimen was collected in the cave on a dry bedrock wall.

\section{Etymology}

Named after Gretchen Baker (ecologist at the Great Basin National Park) who played a major role in seeing this project through to the end, as well as taking

Lead role in field visits and collections.

\section{Recognition}

In the key to males (Disney, 2002c) it runs to couplet 6 but is distinguished from the two species of this couplet by its thicker front basitarsi and by the details of the hypopygium.

\section{Megaselia Rondani. 1856}

The Nearctic species of this giant genus are still poorly known. Borgmeier $(1964,1966)$ provides baseline keys. Subsequent revisions and additions are summarized by Disney (1994). Further additions are covered by Disney (2004, 2008), Disney et al (2009) and Disney et al (2010).

\section{Megaselia excuniculus Disney, sp. nov.}

\section{Description}

Male. Frons brown, clearly broader than long, with 60-64 hairs and fairly dense but very fine microtrichia. Supra-antennal bristles (SAs) with the lower pair a little shorter and less robust than upper pair. The antials a little lower on frons than anterolaterals (ALs), and about twice as far from upper SAs as either is from an AL bristle. Pre-ocellars a little closer together than either is from a mediolateral bristle, which is slightly higher on frons. Cheek with 4 bristles and jowl with two that are longer. The subglobose postpedicels brown, without subcutaneous pit sensilla (SPS) vesicles. Palps pale yellow, at most 0.4 times as broad as postpedicel, with 3 long, 1 medium and 3 short bristles and 8 hairs. Labrum dusky straw yellow and about 0.8 times as wide as a postpedicel. Labella pale apart from pale brown bands dorsally towards sides, with only a few short spinules below and their combined widths about 1.2 times as wide as a postpedicel. Thorax brown. Three notopleural bristles and no cleft in front of these. Mesopleuron with 11-12 hairs. Scutellum with an anterior pair of hairs (about as long as those in middle of scutum) and a pos- 
terior pair of bristles. Abdominal tergites brown with small hairs except for longer one at rear of T6 (Fig. 2b). Venter grayish brown, and with hairs on segments 5 and 6 (Fig. 2b). Hypopygium brown, with a yellow brown anal tube, and as Fig. 2. Legs mid and hind femora brown, front femora pale brown and front tibiae and all tarsi straw yellow. Fore tarsus with posterodorsal hair palisade on segments 1-5 and 5 longer than 4. Dorsal hair palisade of mid tibia extends about 0.6 times its length. Hairs below basal half of hind femur a little longer than those of anteroventral row of outer half. Hind tibia with 15-17 only weakly differentiated posterodorsal hairs and spinules of apical combs simple. Wings $1.9 \mathrm{~mm}$ long. Costal index 0.40. Costal ratios $4.4: 1.1-1.2: 1$. Costal cilia (of section 3) $0.12-0.13 \mathrm{~mm}$ long. No hair at base of vein 3 . With 3 axillary bristles, the outer being slightly shorter than costal cilia. Sc not reaching $\mathrm{R} 1$. Thick veins and thin veins 4-6 yellowish brown and 7 paler. Membrane very lightly tinged grey (not evident to naked eye when viewed against a white background). Haltere brown.

\section{Material}

Holotype male, NEVADA: White Pine Co., Lincoln Mine, 15 July 2007, S. J. Taylor, J. K. Krejca, M. E. Slay, C. M. Slay (421 NPS-GRBA, Project 411, Catalog 6873) (UCMZ, 31-132)

\section{Habitat}

Lincoln Mine is located at an elevation of $2621 \mathrm{~m}$. The species was collected on a dry bedrock wall in the entrance zone, where the air temperature was $9.7^{\circ} \mathrm{C}$, soil temperature was $10.8{ }^{\circ} \mathrm{C}$, relative humidity was $52.5 \%$, and ambient light was 1755 lux.

\section{Etymology}

The name means from a mine.

\section{Recognition}

In the keys of Borgmeier (1964) this species will run to couplet 4 or couplet 7 on page 268 , where none of the options apply. It also fails to run down in the keys for other regions.
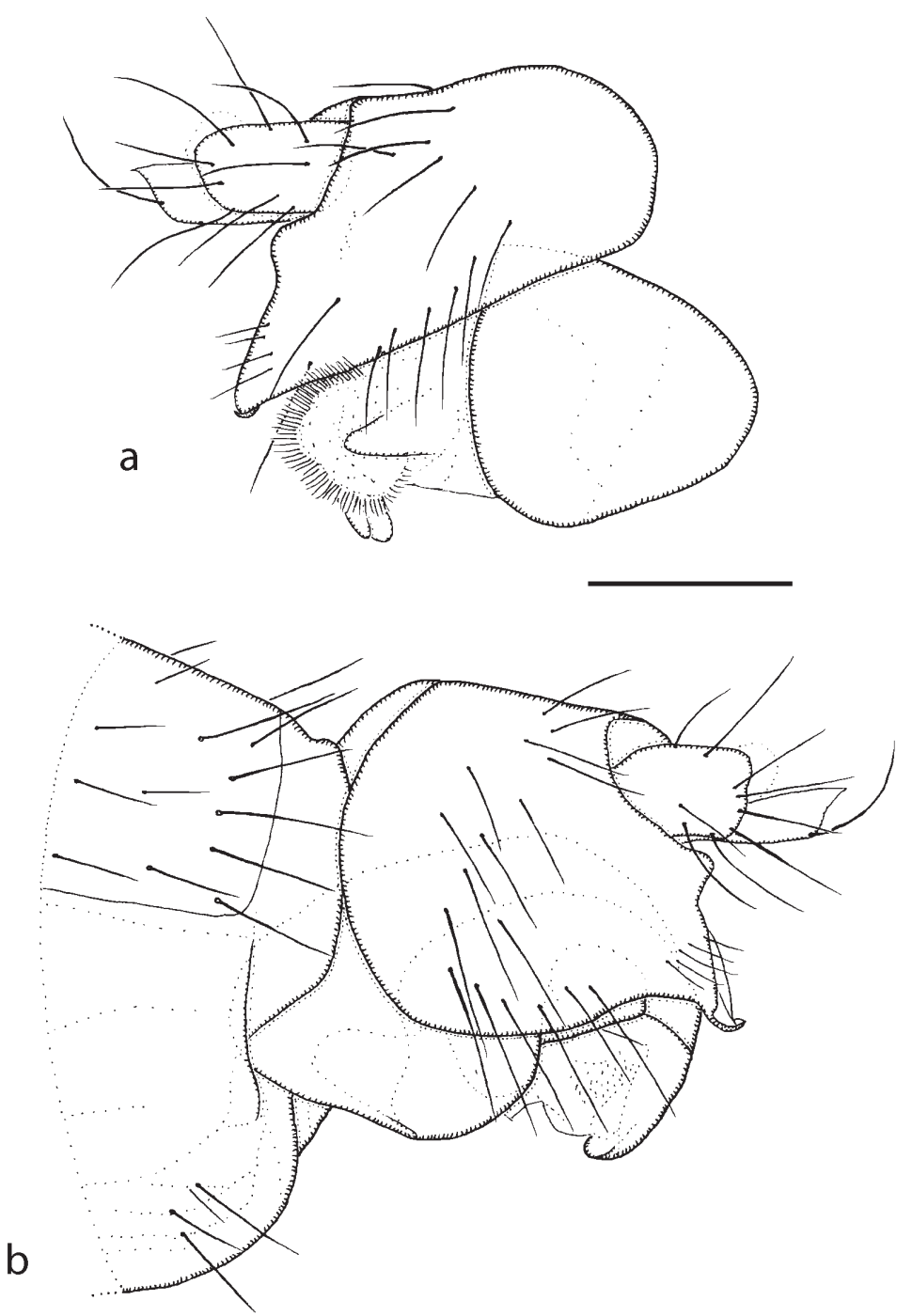

Fig. 2. Megaselia excuniculus sp. nov. male hypopygium. a, right face; $b$, left face. Scale bar $=0.1 \mathrm{~mm}$. 


\section{Megaselia krejcae Disney, sp. nov.}

\section{Description}

Male. Frons brown, clearly broader than long, with 24-30 hairs and numerous but very fine microtrichia. Supra-antennal bristles (SAs) with the lower pair clearly shorter and less robust than upper pair. The antials a little lower on frons than anterolaterals, which are very slightly lower than the upper SAs, and at least 3 times as far from upper SAs as either is from an AL bristle. Pre-ocellars slightly closer together than either is from a mediolateral bristle, which is at about the same level on frons. Cheek with 5 bristles and jowl with 2 that are longer. The subglobose postpedicels brown, with about 3 dozen SPS vesicles, the larger being about the same size as the sockets of the lower SAs, and each embraces several small vesicles. Palps with a short brown basal segment and the second segment mainly brown but mostly yellow in the basal third. They are at most two fifths as broad as postpedicel, with 5 long bristles, 2 short bristles and 7-10 hairs. Labrum brown and about 0.6 times as wide as a postpedicel. Labella largely pale apart from brown bands dorsolaterally, together about 0.8 times as broad as a postpedicel, and with very few short spinules below. Thorax brown. Three notopleural bristles and no cleft in front of these. Mesopleuron bare. Scutellum with an anterior pair of hairs (about as long as those in middle of scutum) and a posterior pair of bristles. Abdominal tergites brown with fine hairs that are a little longer at the rear of T6. Venter brownish grey, and with fine hairs on segments 5 and 6 only. Hypopygium mainly brown, with a paler brown anal tube, and as Fig. 3. Legs brown. Fore tarsus with weak posterodorsal hair palisades on segments 1 and 2 , but these are vestigial on segments $3-5$, and 5 slightly longer than 4 . Dorsal hair palisade of mid tibia extends about 0.7 times its length. Hairs below basal half of hind femur longer than those of anteroventral row of outer half. Hind tibia with about 20 only moderately differentiated posterodorsal hairs and spinules of apical combs simple.

Wings $1.7 \mathrm{~mm}$ long. Costal index 0.40. Costal ratios 3.8-3.9 : 1.3-1.4 : 1. Costal cilia (of section 3) 0.14-0.15 $\mathrm{mm}$ long. A very small hair at base of vein 3 . With 4 axillary bristles, the outer being shorter than costal cilia. Sc reaching R1. All veins light brown but costa more yellowish. Membrane only slightly tinged grey (not evident to naked eye when viewed against a white background). Haltere knob yellow.

\section{Material}

Holotype male, NEVADA: White Pine Co., Cave 24, 17 July 2007, G. M. Baker, S. J. Taylor (459 NPS-GRBA, Project 411, Catalog 7074) (UCMZ, 31-132).

\section{Habitat}

Cave 24 is located at an elevation of $3013 \mathrm{~m}$. The species was collected on the cave floor in a mixture of soil, pine needles, and rocks, in the twilight zone, where the air temperature was $6.6{ }^{\circ} \mathrm{C}$, soil temperature was $5.5^{\circ} \mathrm{C}$, relative humidity was $82.6 \%$, and ambient light was 120 lux.

\section{Etymology}

Named after Jean Krejca.

\section{Recognition}

In the key of Borgmeier (1966) it runs to couplets 7 lead 2 or couplet 10 lead 1 , as at couplet 5 the separation is between species with bristles on the epandrium and those with hairs only. With M. krejcae there are hairs and two very short bristles on the left side but hairs only on the right side. At both couplets the hypopygium is obviously different, the very short anal tube being especially noteworthy.
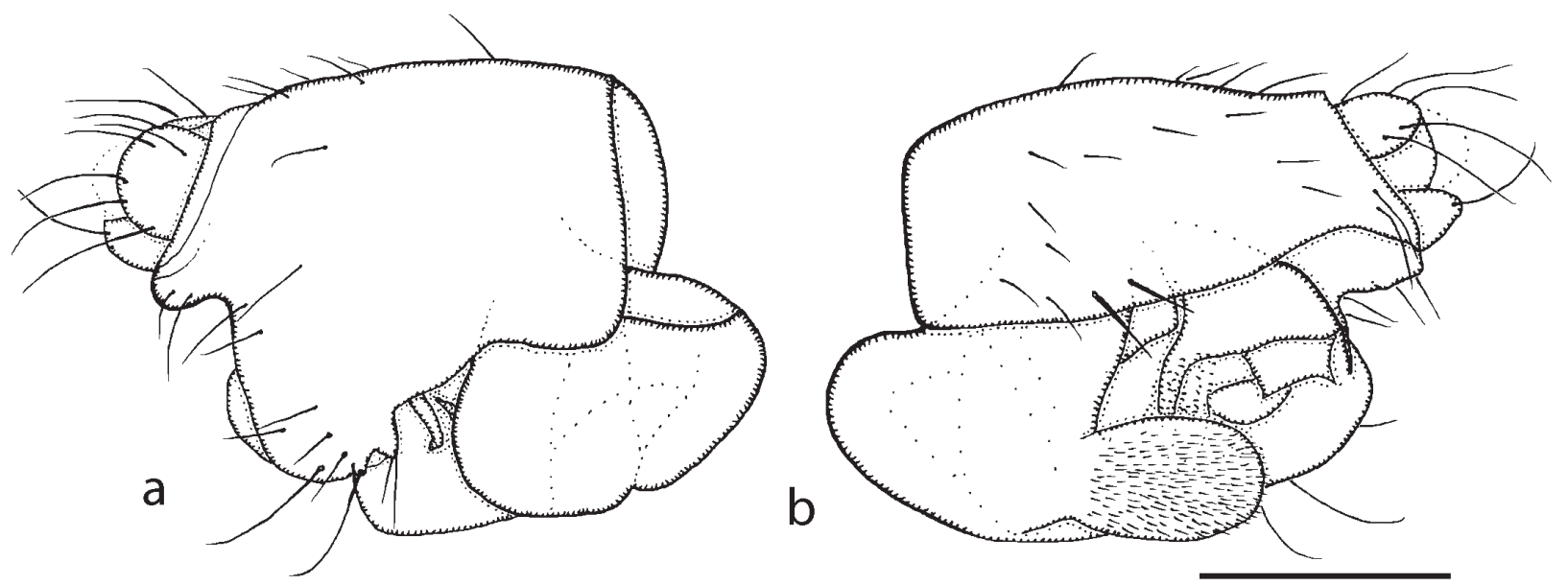

Fig. 3. Megaselia krejcae sp. nov. hypopygium. a, right face; $b$, left face. Scale bar $=0.1 \mathrm{~mm}$. 


\section{Megaselia folliculorum Disney, sp. nov.}

\section{Description}

Male. Frons brown, clearly broader than long, with 80-88 hairs and not very dense but very fine microtrichia. Supra-antennal bristles (SAs) with the lower pair not quite as robust and long as upper pair. The antials lower on frons than anterolaterals, and about as far from upper SAs as either is from an AL bristle. Pre-ocellars about as far apart as either is from a mediolateral bristle, which is at about the same level on frons. Cheek with 5 bristles and jowl with two that are longer. The subglobose postpedicels brown, with 1-2 small SPS vesicles. Palps with a short brown basal segment and pale dusky yellow segment 2, which has 3 long bristles at tip (longer than upper SAs), 5-6 short bristles and up to 10 hairs. Labrum dusky straw yellow and about 0.8 times as wide as a postpedicel. Labella coloured as labrum, about 1.2 times as wide as a postpedicel and with only a few short spinules below. Thorax brown. Three notopleural bristles and no cleft in front of these. Mesopleuron bare. Scutellum with an anterior pair of hairs (about as long as hairs in front of prescutellar dorsocentral bristles) and a posterior pair of bristles. Abdominal tergites brown with numerous fine hairs and longer ones at rear of T6. Venter brownish grey, and with fine hairs on segments 3-6. Hypopygium mainly brown, including the paler brown anal tube, and as Fig. 4. Legs brown to yellowish brown with the front legs being paler than the rest. Fore tarsus with posterodorsal hair palisade on segments 1-4 and basitarsus with 1 to 1.5 rows of hairs below reduced to small spinules. Dorsal hair palisade of mid tibia extends at most two thirds of its length. Hairs below basal half of hind femur about as long as those of anteroventral row of outer half. Hind tibia with at least 16 differentiated posterodorsal hairs and spinules of apical combs simple. Wings 1.6-1.7 mm long. Costal index 0.37. Costal ratios $6.0: 1.5-1.6: 1$. Costal cilia (of section 3 ) $0.11-0.12 \mathrm{~mm}$ long. Two very small hairs at base of vein 3 . With 3 axillary bristles, the outer being about as long as costal cilia. Sc not reaching R1. Thick veins yellowish brown thin veins 4-6 light brown and 7 paler. Membrane lightly tinged grey (just evident to naked eye when viewed against a white background). Haltere knob light brown.
Female. Head similar to male but labrum brown and about as wide as diameter of postpedicel. Otherwise head similar to male. Thorax as male. Abdominal tergites brown and T5-T7 as Fig. 5b. Venter brown, with hairs below segments 3-6, and below the spiracles on segment 4 there is an eversible balloon shaped structure. Sternite 7 very narrow, with 6 small hairs and 3 longer ones at its slightly wider rear end. Posterolateral lobes at rear of sternum 8 pale brown and as Fig. 5a. Cerci pale brown and about 2.8 times as long as broad. Furca not evident. Dufour's crop mechanism pale, narrow in posterior half, and more than 4 times as long as its greatest breadth. Legs similar to male. Wing as male except $1.9-2.0 \mathrm{~mm}$ long. Costal index 0.39. Costal ratios 3.4-5.3 : 1.0-1.8 : 1. Costal cilia $0.12 \mathrm{~mm}$ long. A single hair or none at base of vein 3. With 4-5 axillary bristles, the outermost being longer than costal cilia. Otherwise it and haltere as male.

\section{Material}

Holotype male, NEVADA: White Pine Co., Cave 24, 17 July 2007, G. M. Baker, S. J. Taylor (459 NPSGRBA, Project 411, Catalog 7073) (UCMZ, 31-132). Paratypes: 1 female as holotype except (457, Catalog 7141) (UCMZ, 31-131); 1 female, Lincoln Mine, 15 July 2007, S. J. Taylor, J. K. Krejca, M. E. Slay, C. M. Slay (423 NPS-GRBA, Project 411, Catalog 6886) (UCMZ, 31-132).

\section{Habitat}

This species was collected at two sites, ranging from $2621 \mathrm{~m}$ (Lincoln Mine) to $3013 \mathrm{~m}$ (Cave 24) elevation. The species was collected on cave floors in the entrance and twilight zones, where the air temperature ranged from $6.6-9.7^{\circ} \mathrm{C}$, soil temperature ranged from $5.5-10.8$ ${ }^{\circ} \mathrm{C}$, relative humidity ranged from $52.5-82.6 \%$, and ambient light ranged from 120-1755 lux.

\section{Etymology}

The name refers to the balloon like structures on the sides of the female's abdominal segment 4.

\section{Recognition}

In the key of Borgmeier (1966) as the haltere knob is dusky yellow to yellowish brown, the male runs to cou-
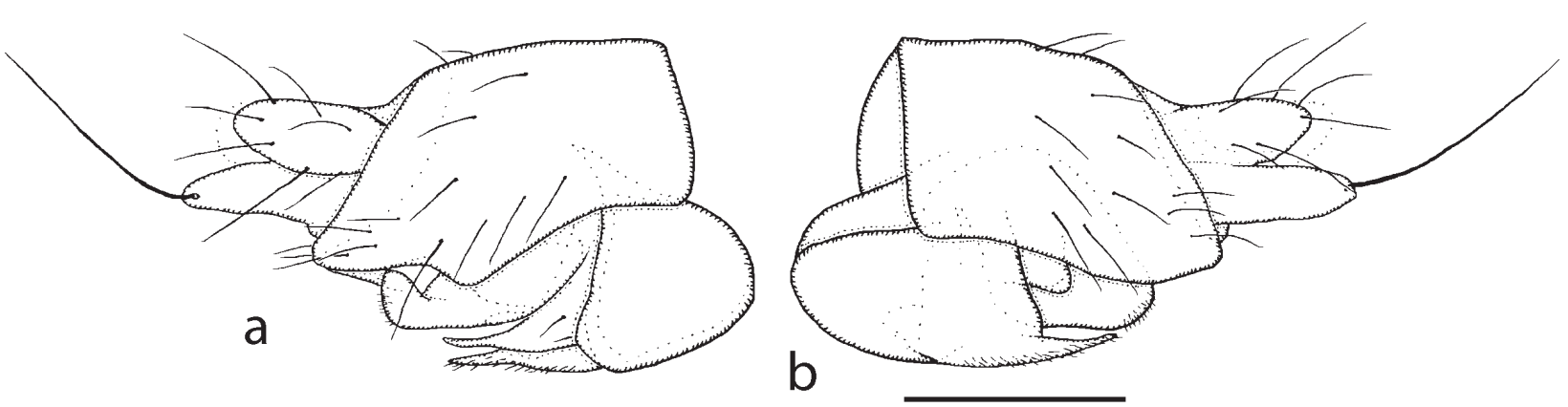

Fig. 4. Megaselia folliculorum male hypopygium. a, right face; $b$, left face. Scale bar $=0.1 \mathrm{~mm}$. 


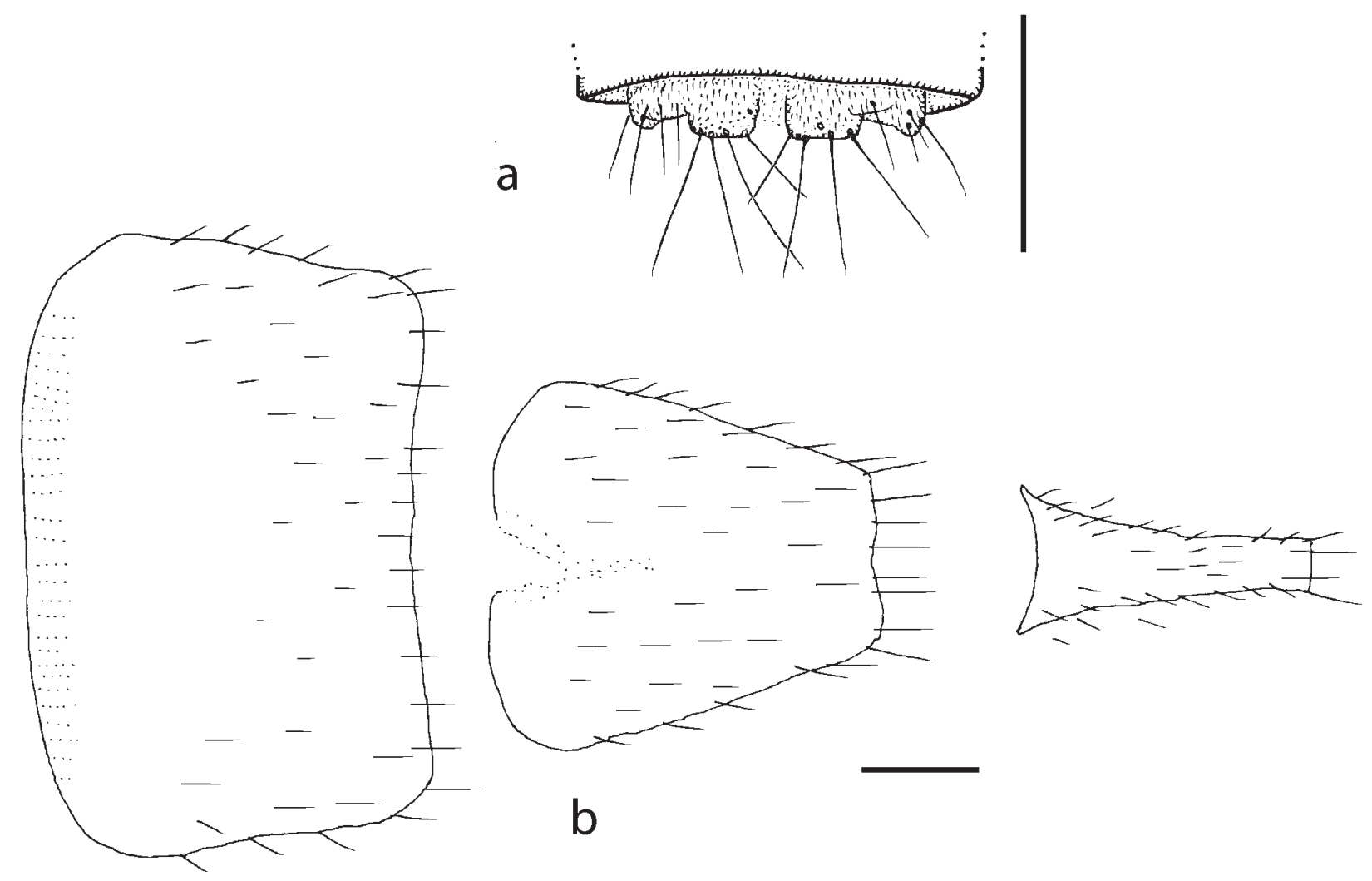

Fig. 5. Megaselia folliculorum sp. nov. female, details of abdomen. a, lobes at rear of ventral face of segment 8; b, tergites 5-7. Scale bars $=0.1 \mathrm{~mm}$.

plet 11 lead 2 on page 6 or to couplet 18 lead 2 on page 7. It is immediately distinguished from M. brevicostalis (Wood) by the presence of 3 bristles on the notopleuron, as opposed to 2 preceded by a notopleural cleft. Furthermore Wood's species is generally much darker. At couplet $18 \mathrm{M}$. folliculorum closely resembles $M$. huachuca Borgmeier, but the latter has a dark brown haltere knob and only 2 axillary bristles, as opposed to 3 in the male and 4 in the females of M. folliculorum. Females cannot be run through Borgmeier's key unless one refers to the males because several couplets are based exclusively on male features.

\section{Megaselia necpleuralis Disney, sp. nov.}

\section{Description}

Male. Frons brown, clearly broader than long, with 40-44 hairs and dense but fine microtrichia. The lower supra-antennal bristles (SAs) almost as long as upper pair and about as far apart as either is from an antial bristle situated at about the same level. The antials about the same level, and 2-3 times as far from upper SAs as either is from an AL bristle. Pre-ocellars slightly closer together than either is from a mediolateral bristle, which is at about the same level on frons. Cheek with 5 bristles and jowl with 2 that are longer and more robust. The subglobose postpedicels brown and without SPS vesicles. Palps pale dusky yellow, at most two thirds as broad as postpedicel, with 5 moderately long bristles, 1-2 very short bristles and up to 10 hairs. Labrum coloured and about as wide as a palp. The two labella combined about 1.7 times as wide as a postpedicel, each with a brown band dorsally and with numerous short spinules below. Thorax brown. Three notopleural bristles and no cleft in front of these. Mesopleuron with 3-8 hairs and a clearly differentiated bristle near hind margin. Scutellum with an anterior pair of hairs (shorter than those at rear of scutum) and a posterior pair of bristles. Abdominal tergites brown with hairs, which are longer at rear of T6. Venter grayish brown, and with hairs on segments 3-6. Hypopygium with brown epandrium and hypandrium, apart from latter's posterior lobes which are straw yellow, with a pale brown anal tube, and as Fig. 6. The right paraphysis of the penis complex as Fig. 7. Legs brown to yellowish brown, the front legs being palest but with the fifth tarsal segment brown. Fore tarsus with posterodorsal hair palisade on segments 1-4 and 5 a little longer than 4. Dorsal hair palisade of mid tibia extends about 0.7 times its length. Hairs below basal half of hind femur shorter than longest hairs of anteroventral row of outer half. Hind tibia with about a dozen differentiated posterodorsal hairs, which are weakly differentiated in the basal third, and spinules of apical combs simple. Wings 2.3-2.6 mm long. Costal index 0.47-0.48. Costal ratios 3.5-4.4 : 2.7-3.7 : 1 . 


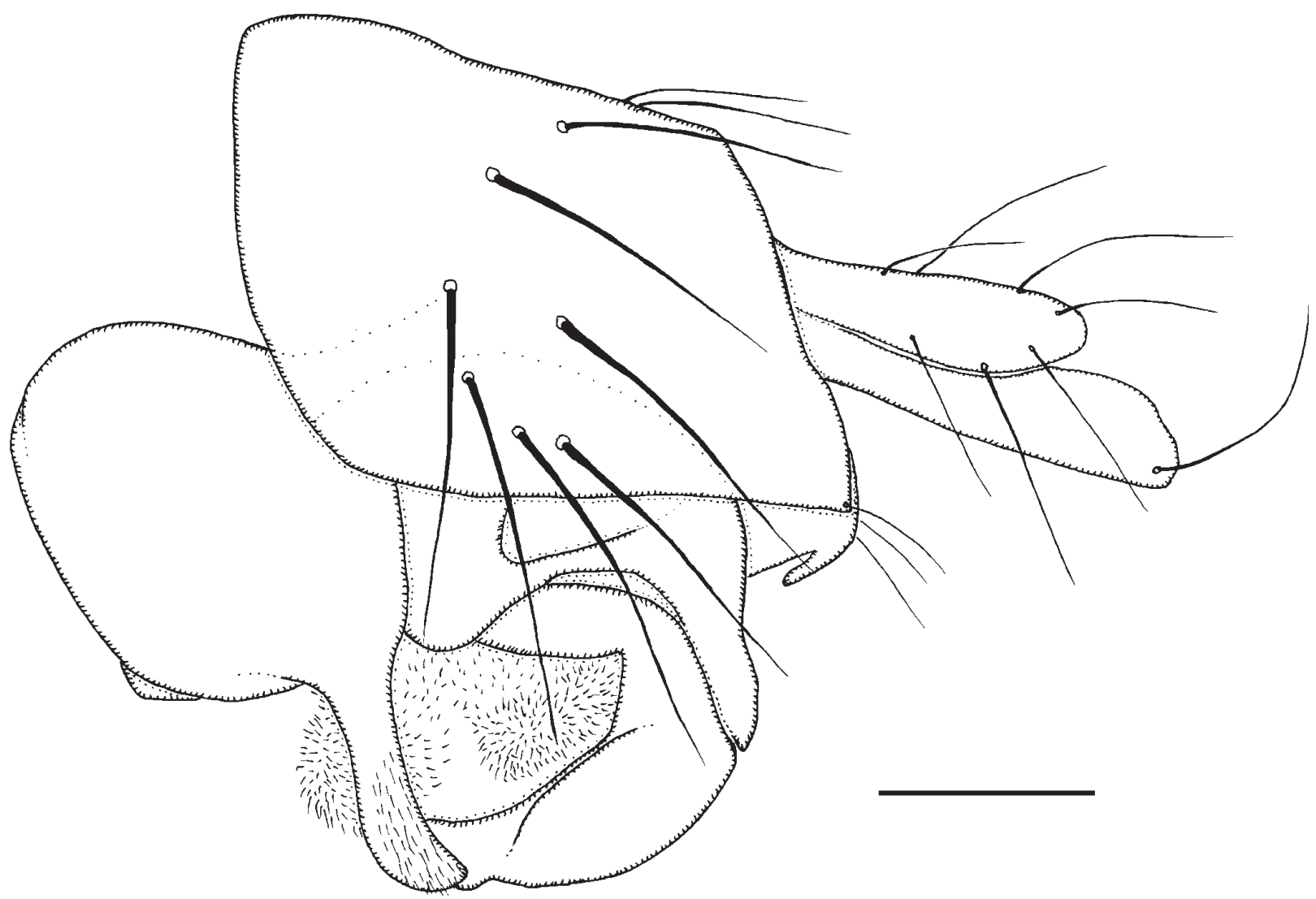

Fig. 6 Megaselia necpleuralis sp. nov. male, left face of hypopygium. Scale bar $=0.1 \mathrm{~mm}$.

Costal cilia (of section 3) $0.19 \mathrm{~mm}$ long. Hair at base of vein 3. With 6-7 axillary bristles, the outer being a little shorter than costal cilia. Sc not reaching R1. Thick veins brown but costa more yellowish brown, thin veins brown but 7 paler and more grey. Membrane lightly tinged grey, being darkest towards leading edge beyond costa (just evident to naked eye when viewed against a white background). Haltere with brown stem and yellow knob.

\section{Material}

Holotype male, NEVADA: White Pine Co., Great Basin National Park, Lehman Cave, under natural entrance, 3 May 2010, G. M. Baker (UCMZ, 31-133). Paratype male as holotype.

\section{Habitat}

Lehman Cave is located at an elevation of $2096 \mathrm{~m}$. The species was collected in the twilight zone, where the air temperature was $9.6^{\circ} \mathrm{C}$, soil temperature was $10.0^{\circ} \mathrm{C}$, and relative humidity was $78.5 \%$.

\section{Etymology}

Named after its close resemblance to $M$. pleuralis (see below).

\section{Recognition}

In the key of Borgmeier (1964) this species runs to couplet 11 on page 264 , where it is excluded by the much shorter hairs below the basal half of the hind femur. At couplet 8 on page 263 it is seemingly excluded from being M. pleuralis (Wood) because its costal index is less than 0.5 . However, this distinction is not valid as the costal index of Palaearctic specimens of $M$. pleuralis ranges from 0.47 to a little over 0.52 or more. The new species is indeed very similar to the Holarctic $M$. pleuralis, whose type series was from England. In view of this 4 males of Nearctic voucher specimens of this species listed by Borgmeier were borrowed by RHLD, through the co-operation of Dr Brian Brown (Natural History Museum, Los Angeles), and were remounted on slides. These specimens were from Glen Echo, Mt Rainer, Priest Lake (Lookout Mountain) and Rock Creek. Their costal indexes range from 0.48 to almost 0.52 (mean 0.49), thus confirming the observed variation in Palaearctic specimens of this species.

The hypopygia of the new species closely resembles that of M. pleuralis (cf Figs 6 and 8). The two species are best distinguished by the details of the penis complex. However, these structures vary in appearance when viewed from different angles, as evidenced by their rotation when withdrawn or extruded (cf Fig. 8 and 9). Nevertheless the larger of the two heavily sclerotised paraphyses (P2 in Fig. 9) is clearly different in the two species (cf. Figs 7 and 10). Furthermore, this paraphysis allows confirmation that Borgmeier's voucher specimens belong $M$. pleuralis and that the Nevada specimens are a new, sibling species. 


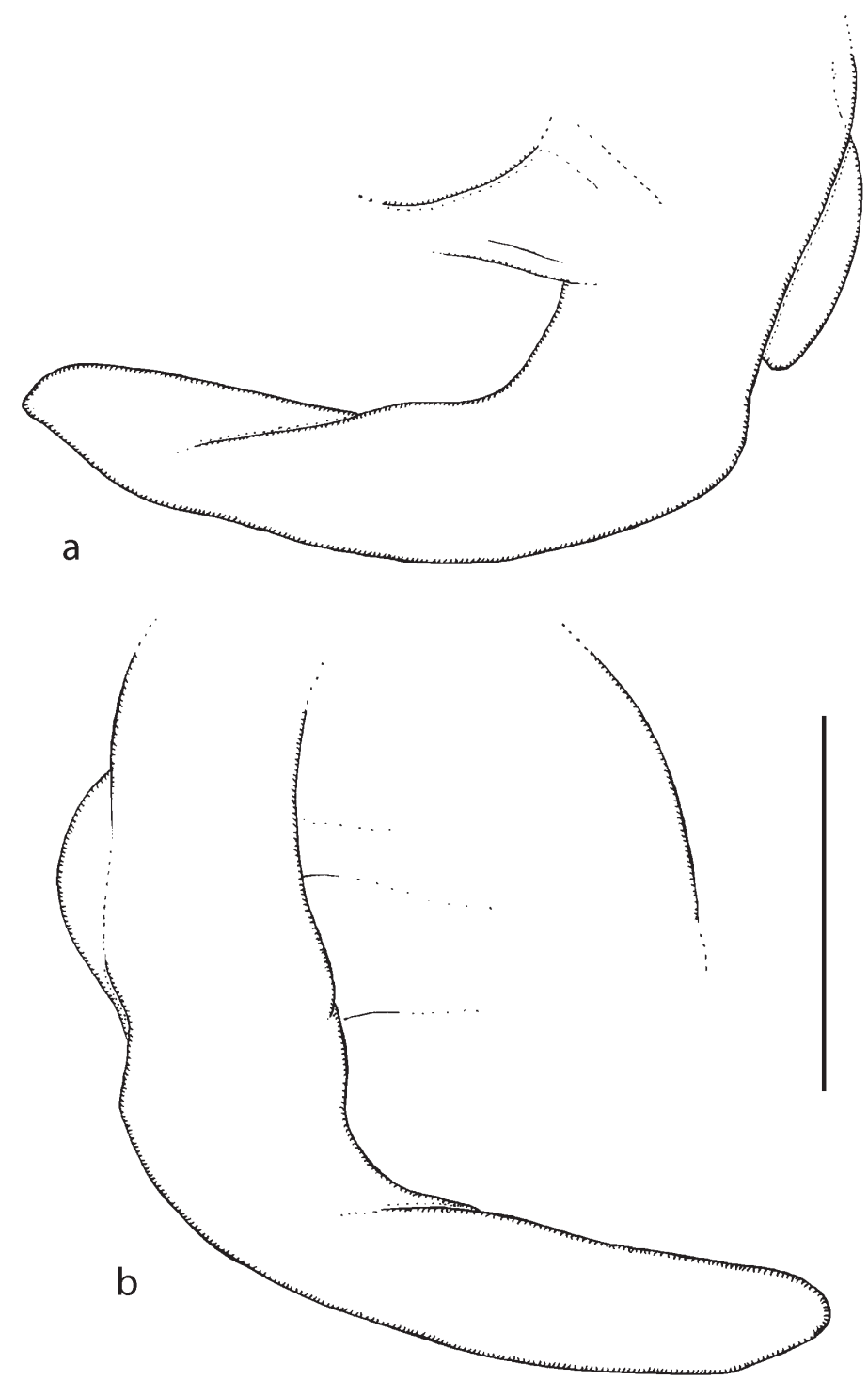

Fig. 7. Megaselia necpleuralis sp. nov. male, right paraphysis of penis complex when withdrawn. a, left face; b, right face. Scale bar $=0.1 \mathrm{~mm}$.

Megaselia sordida (Zettersted)

Trineura sordida Zetterstedt, 1838: 796. Trineura carbonaria Zetterstedt, 1848: 1848. Aphiochaeta alaskensis Malloch, 1919: 52. Aphiochaeta scaura Schmitz, 1921: 322.

Megaselia semiscaura Schmitz, 1927: 130. Megaselia eminens Schmitz, 1953: 219. Disney, 1985: 246.

\section{Remarks}

In the keys of Borgmeier (1964) the males readily run to couplet 15 , on page 266, to M. alaskensis (Malloch), a synonym of $M$. sordida (Zetterstedt), apart from its palps being yellow to dusky yellow. However, the palps of $M$. sordida range from being yellowish brown to grayish brown. Furthermore the legs, wings and colouring in general are paler than typical M. sordida. However, smaller specimens from Europe tend to have paler wings. The specimens from Nevada are at the lower end of the range of variation in size for this species. Although the legs are unusually pale for this species the male hypopygium is indistinguishable from typical M. sordida.

\section{Material}

1 male, NEVADA: White Pine Co., Fissure Cave, 16 July 2007, B. Roberts, M. E. Slay, C. M. Slay (447 NPSGRBA, Project 411, Catalog 7039) (UCMZ, 31-131); 1 male, Lincoln Mine, 15 July 2007, S. J. Taylor, J. K. Krejca, M. E. Slay, C. M. Slay (421 NPS-GRBA, Project 411, Catalog 6872) (UCMZ, 31-132); 1 female, Broken Cave, 16 July 2007, M. Baker, G. M. Baker, B. Roberts, M. Horner (442 NPS-GRBA, Project 411, Catalog 6993) (UCMZ, 31-128). 


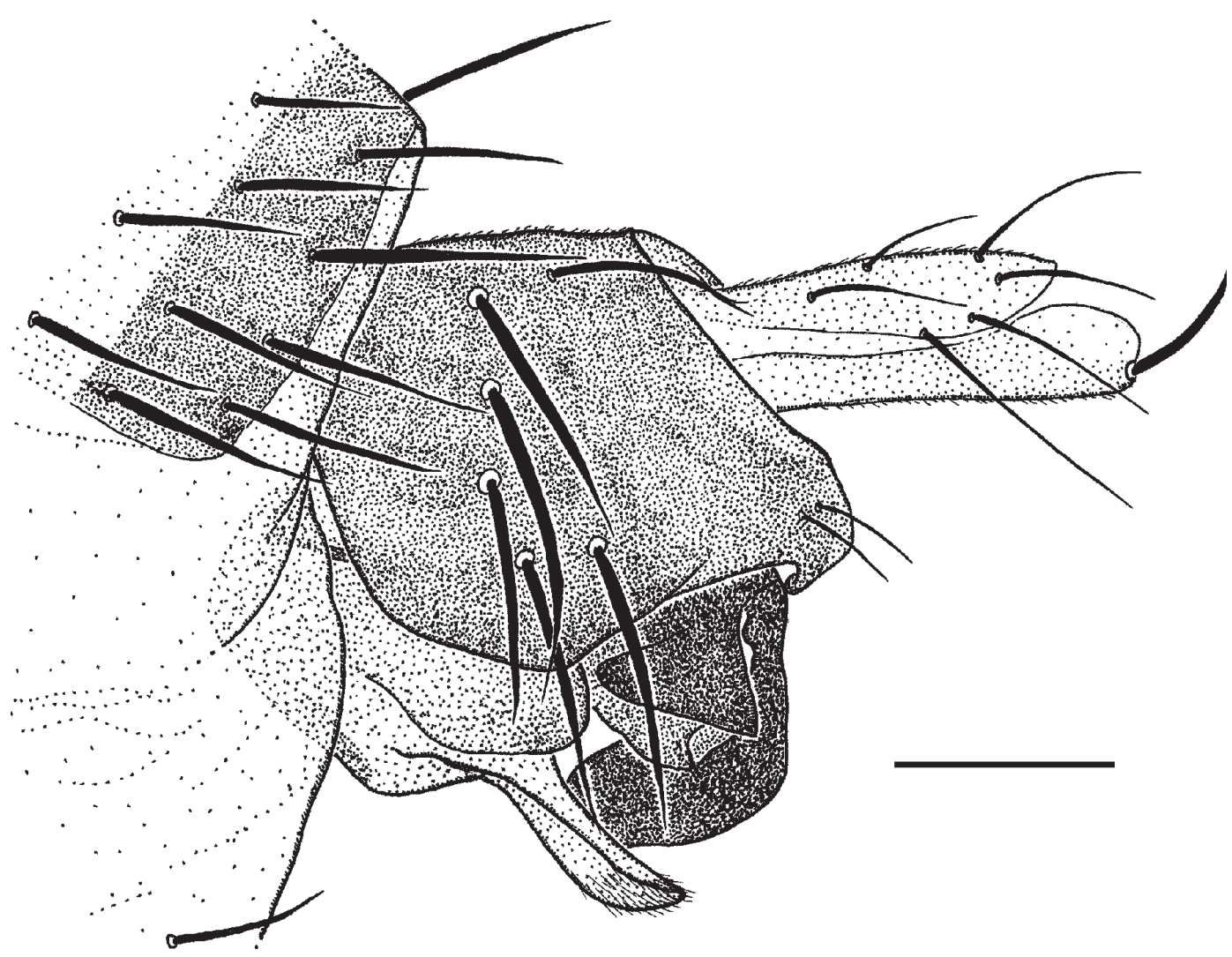

Fig. 8. Megaselia pleuralis male, left face of hypopygium. Scale bar $=0.1 \mathrm{~mm}$.

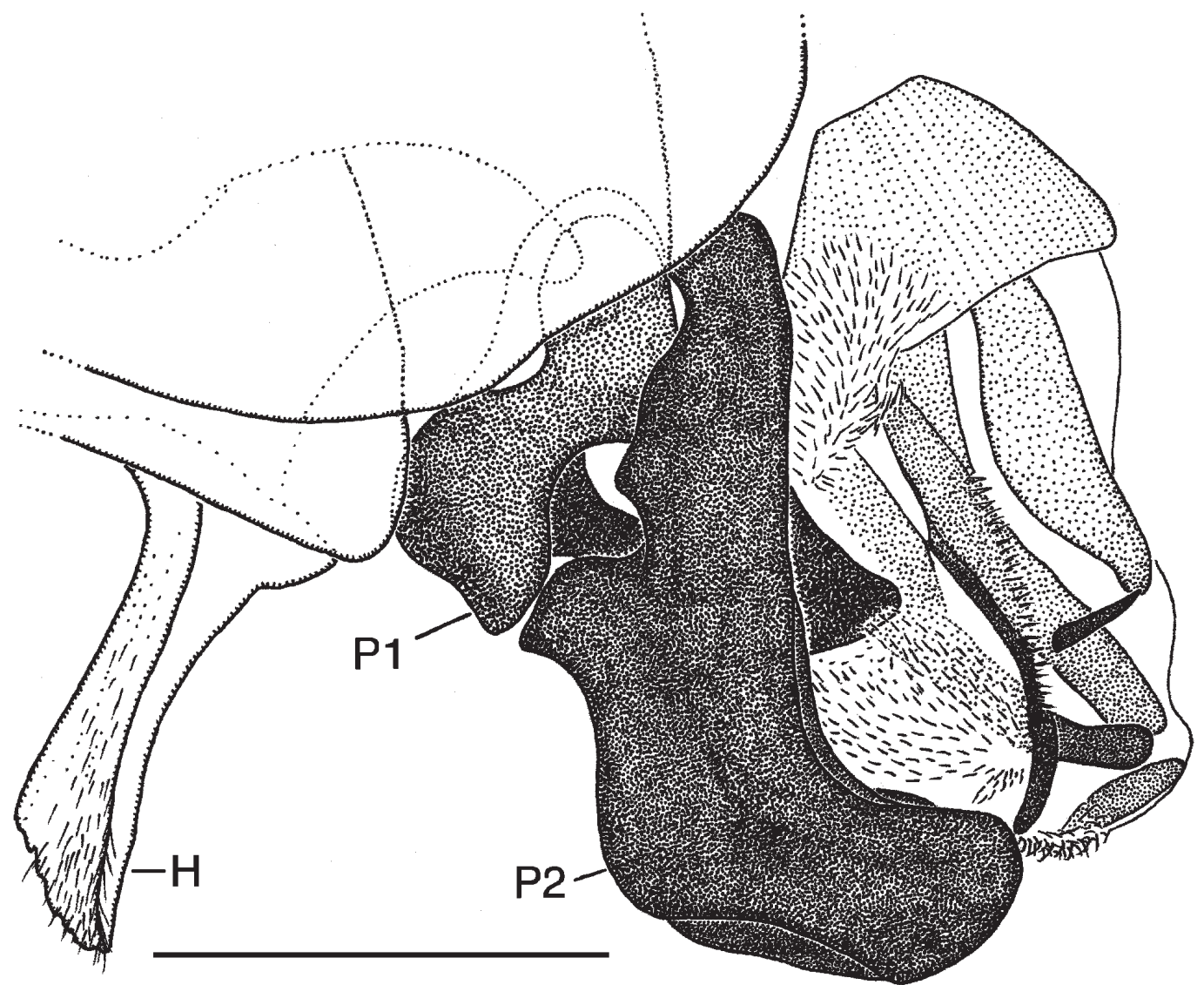

Fig. 9. Megaselia pleuralis male, left face of penis complex when extruded $(\mathrm{H}=$ left lobe of hypandrium, $\mathrm{P} 1$ and $\mathrm{P} 2=\mathrm{left}$ and right paraphyses). Scale bar $=0.1 \mathrm{~mm}$. 

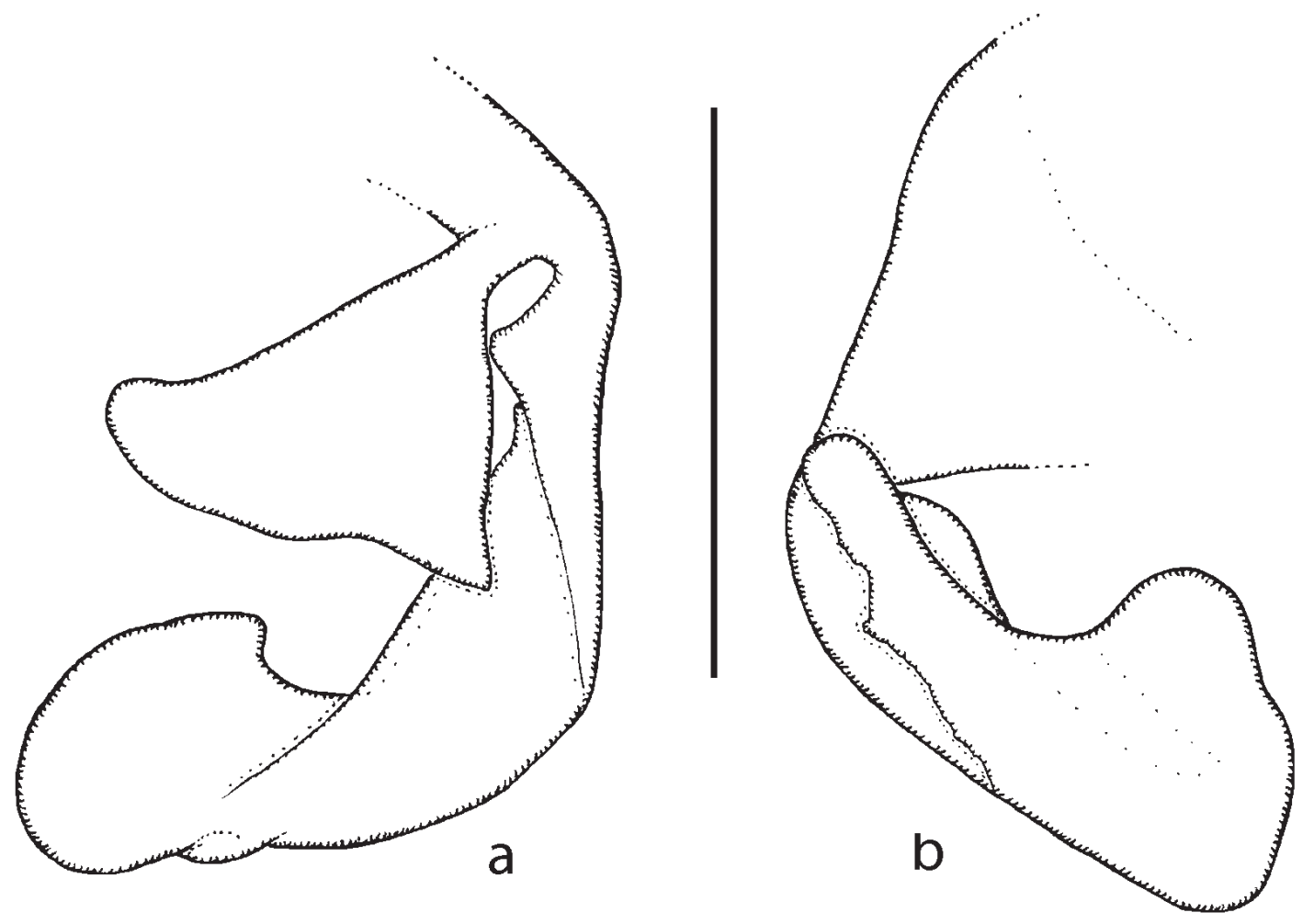

Fig. 10. Megaselia pleuralis male, paraphyses of penis complex when withdrawn. a, left face; $b$, right face of right (larger) paraphysis. Scale bar $=0.1 \mathrm{~mm}$.

\section{Habitat}

This species was collected from three sites, ranging from $2621 \mathrm{~m}$ (Lincoln Mine) to $3407 \mathrm{~m}$ (Broken Cave) elevation. The species was collected on bedrock walls in the entrance and twilight zones, where the air temperature ranged from $9.7-13.9{ }^{\circ} \mathrm{C}$, soil temperature ranged from $10.8-12.1{ }^{\circ} \mathrm{C}$, relative humidity ranged from 52.5 to $52.5-59.2 \%$, and ambient light ranged from $198-1755$ lux.

\section{Megaselia species A}

\section{Remarks}

This cannot be named until linked to its male.

Female. Frons brown and clearly wider than long. The antials closer to anterolaterals than to upper SAs and the lower pair of latter about as strong. Postpedicels subglobose and with at least a dozen SPS vesicles. Palps are mainly brown but with a contrasting yellow patch in their basal halves, and with 5 strong bristles at tip, 1-3 shorter ones behind and about a dozen small hairs. The brown labrum about 1.3 times as broad as a postpedicel. The pale labella combined only about 0.8 times as wide as a postpedicel. Mesopleuron bare. With 2 notopleural bristles and no cleft in front of these. Scutellum with an anterior pair of hairs (about as long as those in middle of scutum) and a posterior pair of bristles. Abdominal tergites brown and with numerous small hairs. Venter brown and with hairs below segments 3-6. Cerci pale brown. Dufour's crop mechanism narrowing in front and to a rounded tip behind. Legs brown but not dark. Front tarsi with long, slender segments. Dorsal hair palisade of mid tibia extends about two thirds of length. Hind femur with hairs below basal half a little shorter than those of the anteroventral row. Hind tibia with about two dozen moderately differentiated posterodorsal hairs and spinules of apical comb simple. Wings 3.3 mm long. Costal index 0.47. Costal ratios 4.1 : 1.8 : 1. Costal cilia $0.22 \mathrm{~mm}$ long. Sc reaches R1. A small hair at base of vein 3 . With 8 axillary bristles which are shorter than costal cilia. All veins brown but costa more yellowish. Membrane only slightly tinged grey (not evident to the naked eye when viewed against a white background). Haltere knob yellow.

\section{Material}

Female, NEVADA: White Pine Co., Indian Burial Cave, 3 March 2007, S. J. Taylor, J. K. Krejca (308 NPSGRBA, Project 411, Catalog 6736) (UCMZ, 31-128).

\section{Habitat}

Indian Burial Cave is located at an elevation of 1724 $\mathrm{m}$. The species was collected on the cave floor on breakdown in the twilight zone, where the air temperature was $9.4{ }^{\circ} \mathrm{C}$, soil temperature was $9.2{ }^{\circ} \mathrm{C}$, relative humidity was $70.6 \%$, and ambient light was less than 1 lux. 


\section{Recognition}

In Borgmeier's (1966) keys it runs to couplet 24 lead 1 on page 4, to $M$. rufipes (Meigen), whose male is highly distinctive but whose female falls within the notoriously difficult $M$. pulicaria complex. However, Dufour's Crop Mechanism narrows towards its rounded rear margin in species A, which immediately distinguishes it from that of $M$. rufipes, which has a pair of pale lobes behind. In species A the palps are mainly brown but with a contrasting yellow patch in their basal halves. In M. rufipes they are entirely yellow.

\section{DISCUSSION}

None of the species collected were taken from the dark zone of caves, but all were taken in areas with reduced light. A nearby weather station (MMTHN2, Baker, Nevada) at an elevation of $2823 \mathrm{~m}$ recorded an average annual relative humidity of $43.8 \%$, with the July average being $32.6 \%$. Our collections were made in cave areas with relative humidity ranging from $52.5 \%$ to $82.6 \%$. These data, then, are consistent with the idea that while these flies may not be troglobitic, but they may be using the cave entrance and twilight zones as a refuge from temperature extremes and the harsh, drying conditions on the surface. Deep cave temperatures fluctuate little, approximate the average annual temperature of the region on the surface, and typically have elevated humidity levels. Studying fauna in caves is an opportunity to learn about organisms that may typically live in inaccessible places in the subsurface such as talus piles, mesocaverns, and soils.

The description of five new species based on sampling only of caves in the southern Snake Range of White Pine County, Nevada, underscores how little we know about the phorid fauna of western North America. It also highlights the degree to which western cave faunas are poorly known. With these five species included, a total of nine new species of invertebrates have been described from caves in Great Basin National Park in less than ten years, including springtails, millipedes and amphipods (see Shear 2007, Shear et al 2009, Zeppelini et al 2009, and Taylor \& Holsinger 2011). Many of these cave sites were never sampled prior to this inventory effort, and during this survey collectors visited some sites only once. Thus, it is likely that more species remain to be discovered with a greater sampling effort.

Effective management of western North American natural resources, especially cave resources, then, may suffer from a lack of knowledge about the true levels of diversity, and, potentially, endemicity, of invertebrate natural communities, at least in cave habitats. Understanding the distribution of species is a key component of successful management strategies. Caves are particularly sensitive to management decisions made in National Parks because they are small features that, in some cases, attract atypically high levels of human visitation. Visitation can compact substrates where invertebrates shelter or forage, alter nutrients via introduction or removal of food substrates, and bring in exotic species. Caves also can collect and store contaminants washed in from entire watersheds. The discovery of so many new species in sensitive cave environments points toward need for continued inventory and taxonomy study

\section{ACKNOWLEDGEMENTS}

We are grateful to Dr Brian Brown (Natural History Museum, Los Angeles) for the loan of voucher material in his temporary care. RHLD's studies of Phoridae are currently supported by grants from the Balfour-Browne Trust Fund (University of Cambridge) and the Systematics Research Fund of the Linnean Society and the Systematics Association (UK). Fieldwork for this study was support by grants from the National Park Service to SJT. Gretchen Baker, Ben Roberts, and Meg Horner were especially helpful, both in the field and in facilitating the fieldwork at Great Basin National Park, Nevada. We thank Christy Slay for her help with collections and data recording. MES acknowledges the Arkansas Field Office of The Nature Conservancy for financial support during this project.

\section{REFERENCES}

Borgmeier, T., 1962. Versuch einer Uebersicht ueber die neotropischen Megaselia- Arten, sowie neue oder wenig bekannte Phoriden verschiedener Gattungen (Dipt. Phoridae). Studia Entomologica, Petropolis. 5: 289-488.

Borgmeier, T., 1963. Revision of the North American phorid flies. Part I. The Phorinae, Aenigmatiinae and Metopininae, except Megaselia (Diptera, Phoridae). Studia Entomologica, Petropolis. 6: 1-256.

Borgmeier, T., 1964. Revision of the North American Phorid flies. Part II. The species of the genus Megaselia, subgenus Aphiochaeta (Diptera, Phoridae). Studia Entomologica, Petropolis. 7: 257-416.

Borgmeier, T., 1966. Revision of the North American Phorid flies. Part III. The species of the genus Megaselia, subgenus Megaselia (Diptera, Phoridae). Studia Entomologica, Petropolis. 8: 1-160 (1965).

Borgmeier, T., 1969. Bredin-Archbold-Smithsonian Biological Survey of Dominica: The Phoridae of Dominica (Diptera). Smithsonian Contributions Zoology. 23: 1-69.

Borgmeier, T., 1971. Further studies on Phorid flies, mainly of the Neotropical Region (Diptera, Phoridae). Studia Entomologica, Petropolis.14: 1-172. 
Disney, R. H. L., 1985. Additions and amendments to the list of British Megaselia (Dipt., Phoridae). Entomologist's Monthly Magazine. 121: 243-248.

Disney, R. H. L., 1989. Scuttle Flies - Diptera Phoridae Genus Megaselia. Handbooks for the Identification of British Insects. 10(8): 1-155.

Disney, R. H. L., 1993. Notes on European Phoridae (Diptera). British Journal of Entomology and Natural History. 6: 107-118.

Disney, R. H. L., 1994. Scuttle Flies: The Phoridae. Chapman \& Hall, London. xii +467 pp.

Disney, R. H. L., 2001. The preservation of small Diptera. Entomologist's Monthly Magazine. 137: 155159.

Disney, R. H. L., 2002. Revisionary notes and new key to Aenigmatias Meinert (Diptera, Phoridae). Fragmenta faunistica. 45: 67-72.

Disney, R. H. L. 2004. A new species of Megaselia Rondani (Dipt., Phoridae) from Arctic Greenland. Entomologist's Monthly Magazine. 140: 309-312.

Disney, R. H. L., 2008. The identification of Megaselia sandhui Disney and M. agarici (Lintner), scuttle fly pests (Diptera: Phoridae) of cultivated mushrooms (Agaricales: Agaricaceae). Entomologist's Gazette. 59: 243-249.

Disney, R. H. L., 2009. Scuttle flies (Dipt., Phoridae) from caves in Spain, including a new species of Megaselia Rondani. Entomologist's Monthly Magazine. 145: 153-156.

Disney, R. H. L. \& J. W. Campbell. 2011. Scuttle flies (Diptera: Phoridae) from caves in Alabama and Georgia, USA. Subterranean Biology. 8: 65-67.

Disney, R. H. L., Copeland, R. S. \& Murrell, E., 2009. The true identity of Copeland's aquatic scuttle fly (Diptera: Phoridae) from Indiana and recognition of a sibling species from Texas. Proceedings of the Entomological Society of Washington. 111: 564-574.

Disney, R. H. L., S. J. Taylor and M. E. Slay. 2010. Review of the scuttle flies (Diptera: Phoridae) recorded from caves in the USA, with new records from Arkansas and Missouri. Subterranean Biology. 7: 75-96.
Malloch, J. R., 1919. The Diptera collected by the Canadian Arctic Expedition (excluding the Tipulidae and Culicidae). Ottawa: Report of the Canadian Arctic Expedition. 3c: 34c-90c.

Schmitz, H., 1921. Neue europäische Aphiochaeta-Arten IV. (Phoridae, Dipt.). Entomologische Berichten de Nederlandsche Entomologische Vereeniging. 5: 319327.

Schmitz, H., 1927. Revision der Phoridgattungen, mit Beschreibung neuer Gattungen und Arten. Natuurhistorisch Maandblad. 16: 30-40, 45-50, 59-68, 72-79, 92-100, 110-116, 128-132, 142-148, 164, 176.

Schmitz, H., 1953. Vier neue Megaselia aus dem Österreichischen Alpen. Tijdschrift voor Entomologie. 96: 219-225.

Schmitz, H., 1955. Phoridae. In: Lindner E (ed.), Die Fliegen der palaearktischen Region 4(33) (Lieferung 180): 321-368. Stuttgart, E. Schweizerbart'sche Verlagsbuchhandlung.

Shear, William A. 2007. Cave millipeds of the United States. V. The genus Idagona Buckett \& Gardner (Chordeumatida, Conotylidae, Idagoninae). Zootaxa 1463: 1-12.

Shear, William A., Steven J. Taylor, J. Jut Wynne, \& Jean K. Krejca. 2009. Cave millipeds of the United States. VIII. New genera and species of polydesmidan millipeds from caves in the southwestern United States (Diplopoda, Polydesmida, Macrosternodesmidae). Zootaxa 2151: 47-65.

Taylor, Steven J. \& John R. Holsinger. 2011. A new species of the subterranean amphipod crustacean genus Stygobromus (Crangonyctidae) from a cave in Nevada, USA. Subterranean Biology 8: 39-47

Zeppelini, D., Steven J. Taylor, \& Michael E. Slay. 2009. Cave Pygmarrhopalites Vargovitsh, 2009 (Collembola, Symphypleona, Arrhopalitidae) in United States. Zootaxa 2204: 1-18.

Zetterstedt, J. W., 1838. Dipterologis Scandinaviae. Sect. 3: Diptera. In Insecta Lapponica. 1-3: 1-868.

Zetterstedt, J. W., 1848. Diptera Scandinaviae disposita et descripta. Lundae. 7: 2581-2934. 